\title{
Management Strategy Based on Genetic Algorithm Optimization for PHEV
}

\author{
Zhang $\mathrm{Yu}{ }^{1}, *$ Meng Dawei ${ }^{1}$,Zhou Meilan ${ }^{1}$ and Lu Dengke ${ }^{2}$ \\ ${ }^{l}$ Department of Electrical Engineering, Harbin University of Science and \\ Technology, Harbin 150080, China \\ ${ }^{2}$ Shenzhen Institutes of Advanced Technology, Chinese Academy of Sciences, \\ Shenzhen 518055, China \\ zhangyu8419@163.com
}

\begin{abstract}
Aiming at the refitted HAFEI hybrid electric vehicle (HEV), fuzzy logic energy management strategy is constructed based on genetic algorithm optimization. The difference value $D$ between the total require torque $\operatorname{Tr}$ of path and the target required torque Te of engine, the intelligence quotient value with Tr is selected as the first input variable of fuzzy controller, the SOC of battery as the second input variable; torque control coefficient $C$ is selected as output variable, meanwhile two input variable membership function is improved on genetic algorithm. To further evaluate the control strategy, dynamic programming control strategy is used as standard; the simulation experiments show that every kind of gas emission is obviously reduced by $12 \%$ to $47 \%$ in fuzzy control strategy B based on genetic algorithm optimization compared to strategy A based on determinacy rules. Compared to dynamic programming, fuel economy in strategy $A$ is only $45.09 \%$ of standard value which is not ideal, the utilization of fuel is low and the gas emission is serious, while in strategy B fuel economy is $78.89 \%$ of standard value and effect is improved obviously.
\end{abstract}

Keywords: PHEV, Energy Management Strategy (EMS), State of Charge (SOC), Fuzzy Logic Control, Genetic Algorithm

\section{Introduction}

There are two sources of power in PHEV, they are motor and engine. They can work alone, also can be used to drive the vehicle together. When the power of battery is sufficient, it will achieve the pure electric mode, thereby reducing fuel consumption and exhaust emissions; when the power of battery is insufficient, the engine will begin to work; when the vehicle needs more power, the motor and the engine will work at the same time. The concrete structure is shown in Figure 1.

The detail parameters of the vehicle are as follows: vehicle cross weight is $1580 \mathrm{~kg}$ and curb weight is $1280 \mathrm{~kg}$. The height of gravity center is $508 \mathrm{~mm}$ at the full load state. The wheelbase is $2600 \mathrm{~mm}$. The distance from center of mass to the front axle is $1470 \mathrm{~mm}$. The distance from center of mass to the back axle is $1130 \mathrm{~mm}$. The wind resistance coefficient is 0.335 . Windward area is $2.31 \mathrm{~m}^{2}$. The rolling resistance coefficient is 0.009 . The wheel radius is $289 \mathrm{~mm}$, the refitted HFJ7161 prototype PHEV is shown in Figure 2. 


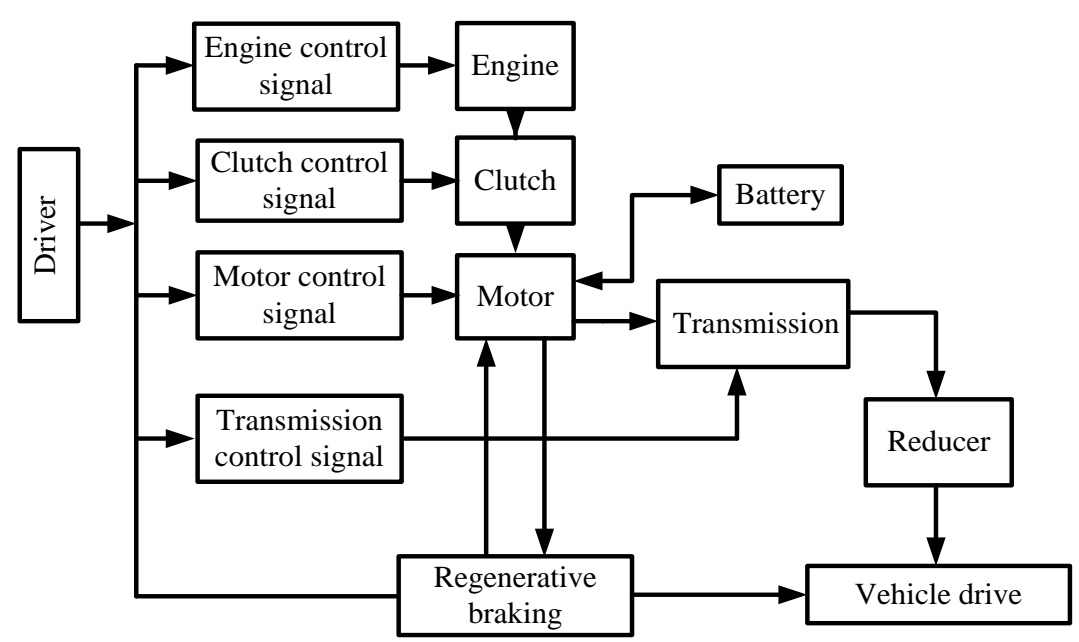

Figure 1. Energy System Structure of PHEV

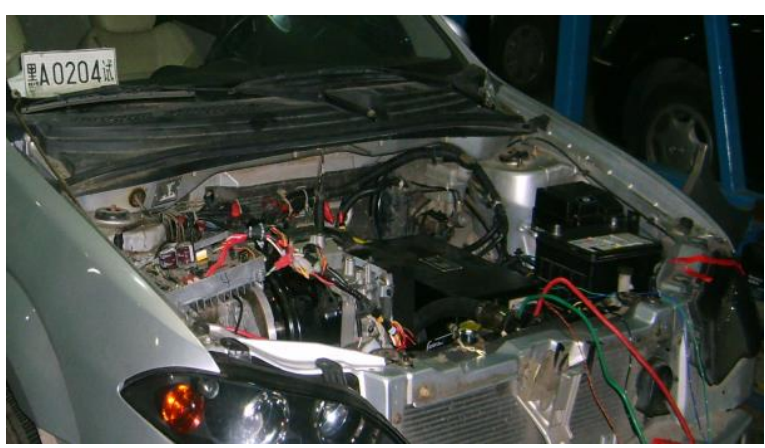

Figure 2. The Refitted HFJ7161 Prototype PHEV

\section{Design of Fuzzy Controller based on Particle Swarm Optimization with Compressibility Factor}

\subsection{The Design Principle of Fuzzy Logic Control Strategy}

The input variables of the fuzzy controller are selected in this paper at first; then the difference value $\mathrm{D}$ between the total require torque $\operatorname{Tr}$ of path and the target require torque $\mathrm{Te}$ of engine is calculated, the intelligence quotient value with $\mathrm{Tr}$ is as the first input variable, the SOC of the battery is as the second input variable; torque control coefficient $\mathrm{C}$ as a fuzzy controller is selected as output variables. Finally the torque distribution is finished between the motor and engine according to the coefficient $\mathrm{C}$. The structure of fuzzy logic controller is shown in Figure 3:

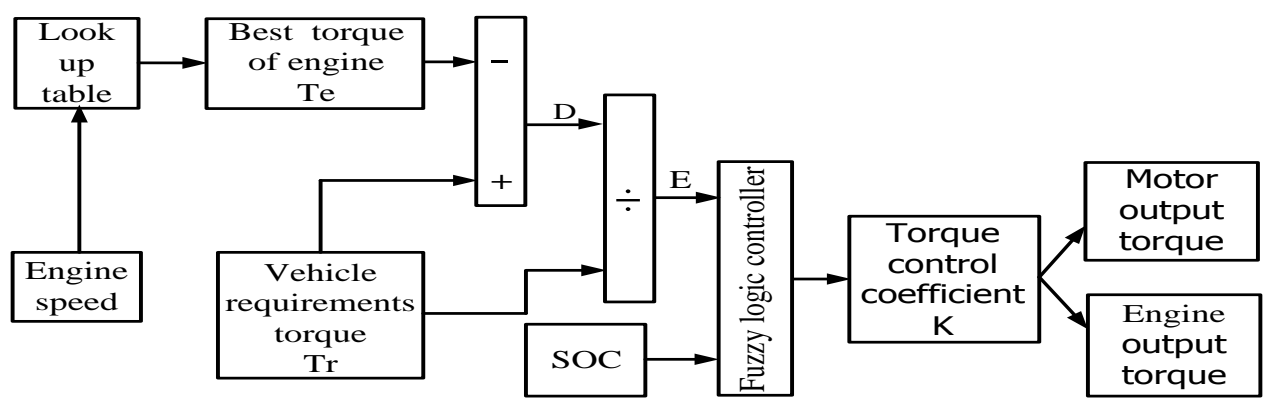

Figure 3. The Structure of Fuzzy Logic Controller 
As $\mathrm{C}$ is not continuous but the specific values, Takagi-Sugeno fuzzy logic controller is chosen; the input variable $\mathrm{E}$ using the trapezoidal membership function, the fuzzy subset is: $\{\mathrm{NB}, \mathrm{NS}, \mathrm{O}, \mathrm{PS}, \mathrm{PB}\}$, the domainis: $\{-60,60\}$; the $\mathrm{SOC}$ of the battery using trapezoidal membership function, the fuzzy subset is: $\{\mathrm{NB}, \mathrm{NS}, \mathrm{O}, \mathrm{PS}, \mathrm{PB}\}$, the domain is: $\{0,1\}$, among which NB represents the negative large, NS represents the negative small, $\mathrm{O}$ represents zero, PS represents the positive small, $\mathrm{PB}$ represents the positive large; the output variable $\mathrm{C}$ using exact value, whose values are: $\{0,75,80,85,90,100,105,110,115$, 120,125 \}according to the demand of the simulation analysis and previous experience gained from the experiments. The membership function curves of two input variables respectively are shown in Figure 4 and Figure 5.

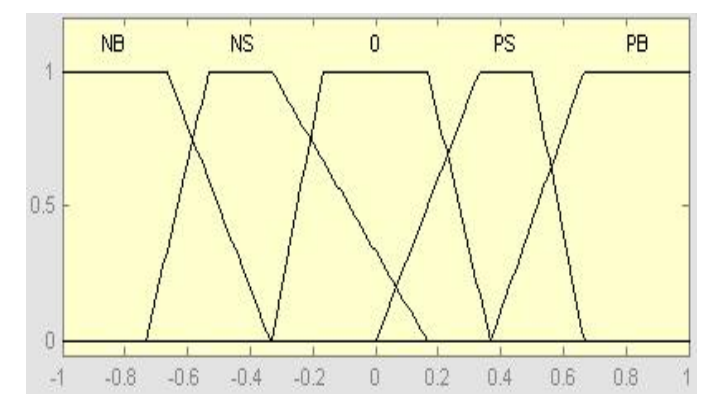

Figure 4. Membership Function of the Input Variable E

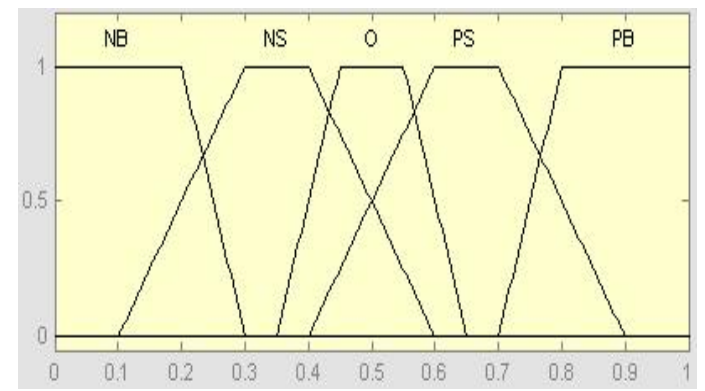

Figure 5. Membership Function of Input Variable SOC

Table 1. Fuzzy Logic Rules library

\begin{tabular}{c|l|l|l|l|l}
\hline & & & & \\
\end{tabular}

\subsection{The Fuzzy Logic Control Strategy Model}

The corresponding fuzzy logic control strategy model is built based on the platform of electric vehicle simulation software ADVISOR in MATLAB/Simulink, the control strategy model and top interface model are as shown in Figure 6. 


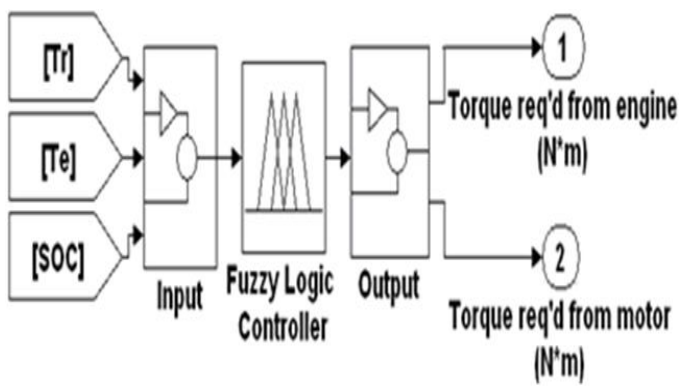

Figure 6. Fuzzy Logic Control Strategy Model

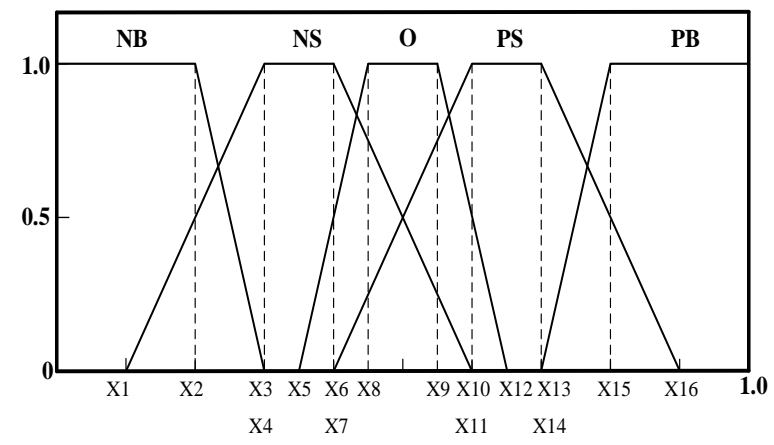

Figure 7. SOC Membership Function Demarcation Points

\subsection{Fuzzy Logic Control Based on Genetic Algorithm Optimization}

\subsubsection{Initial Population}

Soc membership function demarcation points are shown from Figure $7, \mathrm{X} 1 \sim \mathrm{X} 16$ are described as the division points of membership function. And then they are encoded, onedimensional decimal matrix with length 16 will be generated.

The initial population is composed $\mathrm{n}$ chromosomes; the digits of each chromosome are " 0 " or "1" binary number. By definition of membership function, each division point act as a decimal number, considering the coding accuracy, coding of each variable is accurate to three decimal. While the SOC domain is [0,1], at least to be divided into 1000 small intervals. Namely:

$$
512=2^{9}<1 \times 10^{3}<2^{10}=1024
$$

So to define each decimal number, it is represented by a 10-bit binary digit, so that the length of each chromosome is $16 \times 10=160$, for another input variable $\mathrm{E}$ can be used the same method to obtain the initial population.

\subsubsection{The Fitness Function Selection}

The selection of fitness function, directly impacts on the convergence rate of genetic algorithms and the ability to find the optimal solution, taking into account the dynamic performance of the system requirements, this paper used the indicator function as objective functon:

$$
J(\text { ITAE })=\int_{0}^{\infty} t|e(t)| d t
$$


Where $e(t)$ is the systematic error, $t$ is time, $J$ is the ITAE performance indicators, the adaptability and selectivity of the indicators are good.

Shown from Equation2, $J$ smaller indicates that the result is closer to the optimal. However, in the operation of genetic algorithm selection, fitness value of greater individual is more easily inherited from one generation to the next. So this paper builds the Equation 3 as the final fitness function, where $J(i)$ for the ith individual's ITAE value.

$$
F=\frac{1}{1+J(i)}
$$

\subsubsection{The Determination of Other Operation Parameters}

The choice of operating parameters mainly required for Genetic algorithm are individual encoded string of length $l$, the population size $M$, the crossover probability $P$ , the mutation probability $P_{m}$, and the termination of algebra $n$.According to the experience, the genetic algorithm specific operating parameters as shown in Table 2:

Table 2. Operation Parameters

\begin{tabular}{|c|c|c|c|c|}
\hline $\begin{array}{c}\text { Length } \\
l\end{array}$ & $\begin{array}{c}\text { Population } \\
\text { size } M\end{array}$ & $\begin{array}{c}\text { Probability of } \\
\text { Crossover } P_{c}\end{array}$ & $\begin{array}{c}\text { Probability } \\
\text { of mutation } P_{m}\end{array}$ & Generations $\mathrm{n}$ \\
\hline 160 & 100 & 0.8 & 0.05 & 200 \\
\hline
\end{tabular}

\subsubsection{The Improved Membership Functions}

For the membership functions allocation, by setting the corresponding parameters, the genetic algorithm will be decoded and resorted to get a new membership function. Figure 8 and Figure 9 show the two input fuzzy logic variables before and after being improved by genetic algorithm, where the solid line stands for improved membership function, the dotted line represents the improved membership function.

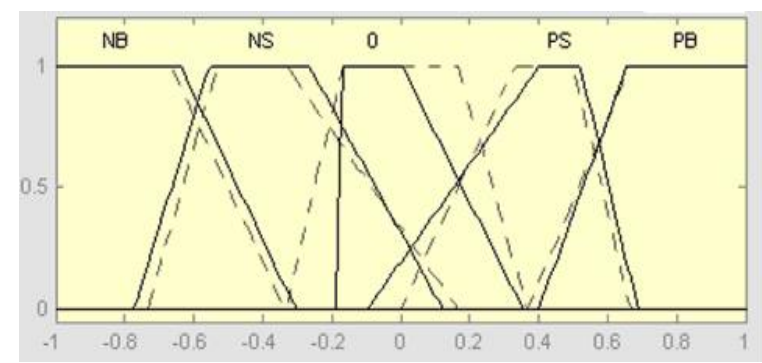

Figure 8. Comparison of Old and New Membership Functions of Input Variable $E$

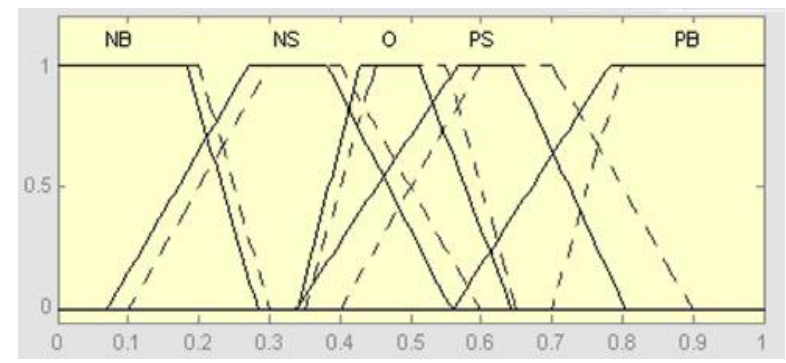

Figure 9. Comparison of Old and New Membership Functions of Input Variable $S O C$ 


\section{Research on Dynamic Programming Control Strategy}

\subsection{The PHEV Model Establishment}

Vehicle performance measurement requires an appropriate dynamics model, which allows us to observe the main dynamic process inside the system in the control process. To reduce the amount of computation, HEV system model has been simplified based on the quasi static principle in this paper. Dynamic process of clutch, gearbox and the affect by temperature on the components are ignored mainly. The vehicle model is established in ADVISOR in Figure 10.

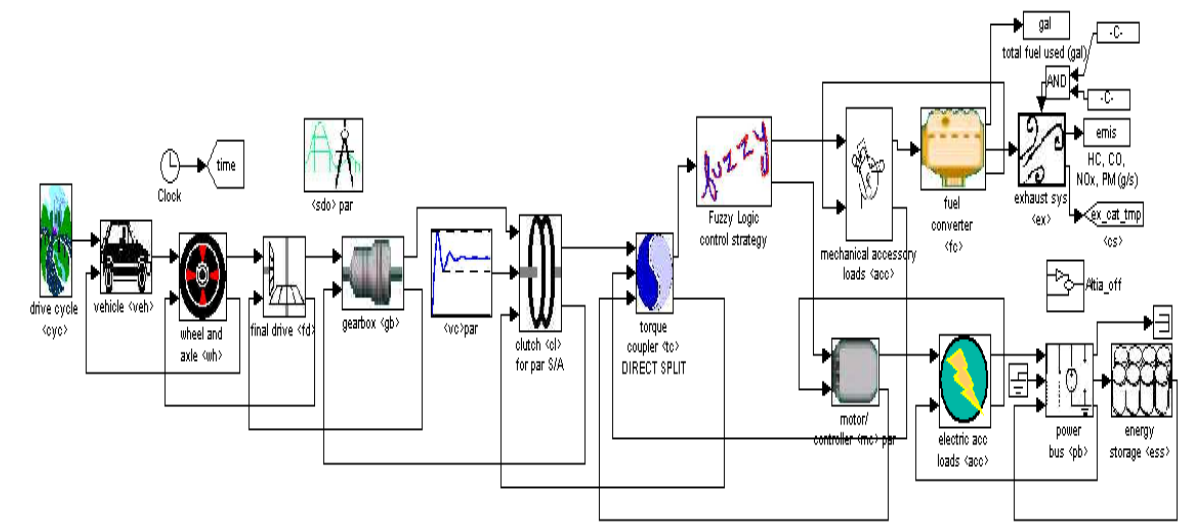

Figure 10. The Vehicle ADVISOR Top Interface Model

\subsection{PHEV Optimization Strategy Establishment}

When the traffic information is known, the dynamic programming approach can be used to realize the PHEV driving force optimization. The goal of dynamic programming optimization is to make the cost function cumulative minimization, the cumulative cost function is also known as the function cost-to-go. The cost function is composed of exhaust emissions, fuel consumption and other additional weighted sum, the form is as follows:

$$
J n(x 0)=\lim _{N \rightarrow \infty} E\left\{\sum_{k=0}^{N-1} \gamma^{k} L(x(k), u(k))\right\}
$$

Among them, $N$ is the lasting time of the driving conditions, $L(x(k), u(k))$ is cost function.

In this paper, the definition of the cost function is as follows:

$$
L\left(X(k), u(k)=L_{\mathrm{fule}}(k)+\alpha L_{\mathrm{ems}}(k)+\lambda L_{\mathrm{soc}}(k)+v L_{\mathrm{gs}}(k)\right.
$$

The cost function must also include constraints of battery charge and discharge balance, which can ensure the battery not appear excessive discharge situation.

$$
L_{\mathrm{soc}}=\left(S O C(k)-S O C_{\mathrm{ref}}\right)^{2}
$$

Among them, $S O C_{\text {ref }}$ is the desired SOC value in the end of driving conditions. In order to maintain the balance of charge and discharge, choose an appropriate positive weighted factor $\lambda$ to ensure the change of SOC not exceed the permitted range.

Shifting control strategy is also very important for fuel economy in PHEV. If do not limit its frequency, shift gear track will be frequent for realizing the optimal control, it will affect the driver's driving comfort and the dynamics vehicle seriously. To deal with this situation, an additional cost function is established to avoid frequent shifting. This additional cost function is expressed using Lgs: 


$$
L_{\mathrm{gs}}=|\operatorname{shift}(k)|
$$

The constraint conditions of optimal control problems are mainly the following aspects:

$$
\begin{gathered}
w_{\mathrm{e}_{-} \min } \leq w_{\mathrm{e}}(k) \leq w_{\mathrm{e}_{-} \max } \\
S O C_{\min } \leq S O C(k) \leq S O C_{\max } \\
T_{\mathrm{e}_{-} \min }\left(w_{\mathrm{e}}(k)\right) \leq T_{\mathrm{e}}(k) \leq T_{\mathrm{e}_{-} \max }\left(w_{e}(k)\right) \\
T_{\mathrm{m}_{\_} \min }\left(w_{\mathrm{m}}(k), S O C(k)\right) \leq T_{\mathrm{m}}(k) \leq T_{\mathrm{m}_{-} \max }\left(w_{\mathrm{m}}(k), S O C(k)\right)
\end{gathered}
$$

For the control problem of PHEV, namely, the output torque of the engine and the gear sequence composed by the following formula:

$$
\pi^{*}=\left\{u^{*}(1), u^{*}(2), \cdots \cdots, u^{*}(N-1),\right\}
$$

For the control space and the continuous state, it should discrete the control variables and state variables into the finite cell point at first. For PHEV, a four-dimensional is composed by the state vector $S=\left(\operatorname{SOC}(k), w_{w}(k), g(k), T_{\text {dem }}(k)\right)$. The movement vector is $A=\left(T_{e}(k), \operatorname{shift}(k)\right)$. Similarly, the wheel speed $w_{w}$ and the SOC will also be discrete into finite concentration. So the total state space composed by a finite point $\left\{S^{i}, i=1,2, \ldots \ldots, N_{s} N_{w} N_{g} N_{r}\right\}$.

$$
\begin{gathered}
w_{\mathrm{w}} \in\left\{w^{1}{ }_{\mathrm{w}}, w^{2}{ }_{\mathrm{w}}, \cdots \cdots, w_{\mathrm{w}}^{N_{\mathrm{w}}}\right\} \\
S O C=\left\{S O C^{1}, S O C^{2}, \cdots \cdots, S O C^{N_{s}}\right\}
\end{gathered}
$$

In order to solve the dynamic programming problem, we need to calculate the cost function of each "state-action". Generally, the cost function matrix take the form of $(s(k), u(k))=\left(L_{\text {jut }}, L_{c a s}, L_{s o c}, L_{s,}, s(k+1)\right)$. When we have known the cost function matrix, it is easy that we can select different parameters through the vector operation in the objective function expression.

In the study, dynamic programming contains three weight coefficients $\alpha, \lambda$ and $v$. With each weight coefficient change, the related term of important degree is changing in the performance index. Selection of weighted coefficient has two basic principles: 1) $\lambda$ meet the constraints of SOC balance; 2) the shift schedule meet the driver's operation habits, not too frequent.

\subsection{The Simulation Experiments Test of Control Strategy}

To test the effectiveness of the strategy, electric vehicle simulation software ADVISOR is used to analyze the results. For the convenience of comparison, simulation experiments based on determinacy rules (strategy A) are done at the same time, the main idea of the strategy is engine is working mainly in the running process, when the output power is not enough, the motor is auxiliary driving. In the end this fuzzy logic control strategy optimized by genetic algorithm(strategy B) is compared with strategy A. Meanwhile aiming at different initial SOC on the same 10 times of UDDS road cycle, experimental tests are made for change of SOC showed from Figure 11 to Figure 14. 
To evaluate fuel economy, MPG is used to evaluate fuel economy. The fuel consumption and exhaust emission of 10 times UDDS cycle road condition when initial SOC is 0.7 showed in Table 3.

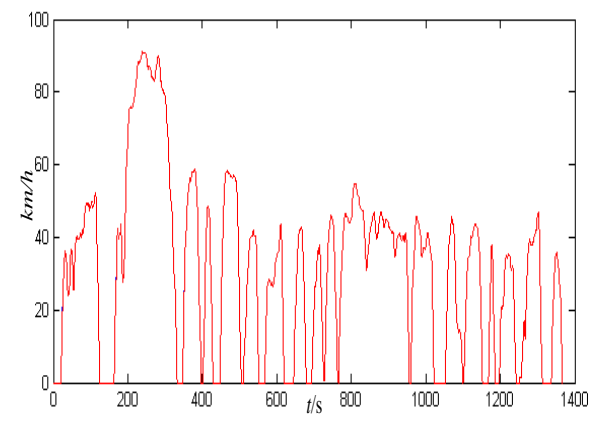

Figure 11. Information of UDDS Road Condition

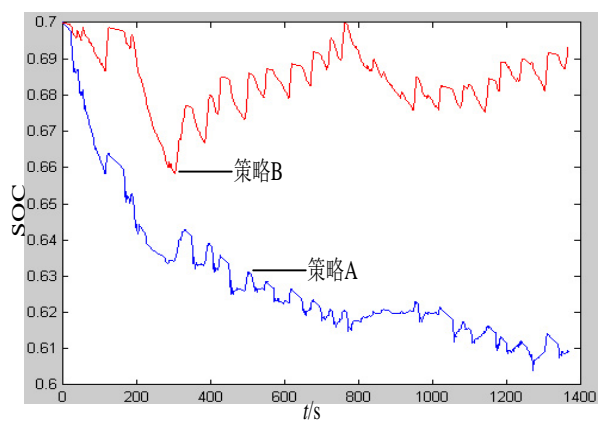

Figure 12. The Changes of SOC under UDDS Road Condition in the Strategy $A$ and $B$

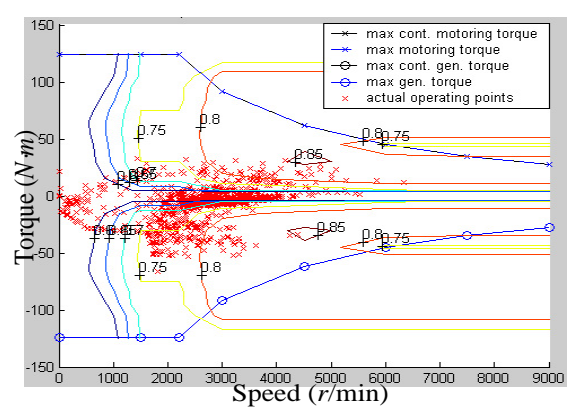

Figure 13. The Operation of Motor under UDDS Road Condition with Strategy A 


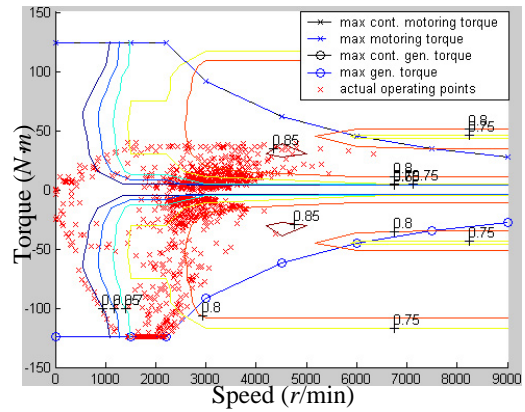

Figure 14. The Operation of Motor under UDDS Road Condition with Strategy B

Table 3. The Fuel Consumption and Exhaust Emission of 10 Times UDDS Cycle Road Condition

\begin{tabular}{c|c|l|l|l}
\hline \multicolumn{2}{c}{ Drive cycle UDDS $\times 10$} & \multicolumn{3}{c}{ Initial value $\mathrm{SOC}=0.7$} \\
\hline \multirow{3}{*}{ Control strategy } & $\begin{array}{c}\text { Fuel } \\
\text { Economy } \\
\mathrm{L} /(100 \mathrm{~km}\end{array}$ & $\begin{array}{l}\mathrm{CO} \\
\text { Emissions } \\
\mathrm{g} / \mathrm{km}\end{array}$ & $\begin{array}{l}\mathrm{HC} \\
\text { Emissions } \\
\mathrm{g} / \mathrm{km}\end{array}$ & $\begin{array}{l}\text { NOx } \\
\text { Emissions } \\
\mathrm{g} / \mathrm{km}\end{array}$ \\
\hline Strategy A & 32 & 1.14 & 0.221 & 0.279 \\
\hline Strategy B & 54.5 & 0.505 & 0.134 & 0.108 \\
\hline
\end{tabular}

In the research, one second is as cycle sampling. The resolution of SOC discretization is 0.005 , the resolution of engine output torque is $1 \mathrm{~N} . \mathrm{m}$, weighted coefficient in cost function is $\alpha=0, \lambda=1000, v=0.5$. The initial and final values are both 0.7.

Table 4. The Simulation Results of Dynamic Programming Control Strategy

\begin{tabular}{c|c}
\hline Drive cycle & dynamic programming \\
\hline Fuel economy (MPG) & 67.75 \\
\hline Energy average use rate of engine (\%) & 35.7 \\
\hline Energy average use rate of motor $(\%)$ & 90.8 \\
\hline
\end{tabular}

The result of fuel economy in dynamic programming control strategy is $67.75 \mathrm{mpg}$ which is considered as the optimal on the UDDS road cycles for HEV; according to the experiments, the MPG 54.5 in strategy B is close to the reference standard than the MPG 32 in strategy A.

\section{Acknowledgement}

This work is supported by the Natural Science Foundation of China (Grant No.51275137) and Heilongjiang Natural Science Foundation (Grant No.E201302).The authors express their gratitude for valuable suggestions and advice from the anonymous reviewers.

\section{References}

[1] R. Carter, A. Cruden, P. J. Hall and A. S. Zaher, "An improved lead acid battery pack model for use in power simulations of electric vehicles", IEEE Trans. Energy Conversions, vol. 27, no. 1, (2012), pp. 2128.

[2] Hegazy, "PSO algorithm-based optimal power flow control of fuel cell/supercapacitor and fuel cell/battery hybrid electric vehicles", the International Journal for Computation and Mathematics in Electrical and Electronic Engineering, (2013), pp. 86-107.

[3] S. Lu, S. Hillmansen and C. Roberts, "A Power-Management Strategy for Multiple-Unit Railroad Vehicles", Vehicular Technology, IEEE Transactions on, vol. 60, no. 2, (2011), pp. 406-420. 
[4] D. Pelusi, "Optimization of a fuzzy logic controller using genetic algorithms", Intelligent Human Machine Systems and Cybernetics (IHMSC), International Conference on, (2011).

[5] C. Zhang and A. Vahidi, "Route Preview in Energy Management of Plug-in Hybrid Vehicles", Control Systems Technology, vol. 20, no. 2, (2012), pp. 546-553.

[6] S. Kelouwani, N. Henao, K. Agbossou, Y. Dubé and L. Boulon, "Two-Layer Energy-Management Architecture for a Fuel Cell HEV Using Road Trip Information”, Vehicular Technology, vol. 61, no. 9, (2012), pp. 3851-3864.

[7] S. G. Li, S. A. Sharkh, F. C. Walsh and C. N. N. Zhang, "Energy and Battery Management of a Plug-In Series Hybrid Electric Vehicle Using Fuzzy Logic", Vehicular Technology, vol. 60, no. 8, (2011), pp. 3571-3585.

[8] D. F. Opila, X.Wang, R. McGee, R. B. Gillespie, J. A. Cook and J. W.Grizzle, "An Energy Management Controller to Optimally Trade Off Fuel Economy and Drivability for Hybrid Vehicles", Control Systems Technology, vol. 20, no. 6, (2012), pp. 1490 - 1505.

[9] H. Khayyam, "Stochastic Models of Road Geometry and Wind Condition for Vehicle Energy Management and Control", Vehicular Technology, vol. 62, no. 1, (2013), pp. 61-68.

[10] Y. L. Murphey, J. Park, L. Kiliaris, M. L. Kuang, M. A. Masrur, A. M. Phillips and Q. Wang, "Intelligent Hybrid Vehicle Power Control—Part II: Online Intelligent Energy Management", Vehicular Technology, vol. 62, no. 1, (2013), pp. 69-79. 